\title{
The effects of an eLearning module "Elderly people in safe hands" for healthcare professionals to challenge elder abuse: a mixed method study
}

\author{
Josien A. Caris , Marian J.M. Adriaansen, Willeke A. Manders \\ HAN University of Applied Sciences, Netherlands
}

Received: April 7, 2016

DOI: $10.5430 /$ jnep.v7n2p62
Accepted: July 28, 2016

Online Published: September 23, 2016

URL: http://dx.doi.org/10.5430/jnep.v7n2p62

\begin{abstract}
One out of twenty elderly people in the Netherlands is being abused. It is important that healthcare professionals are capable of recognizing elder abuse. Therefore, the Dutch Ministry of Health, Welfare and Sport introduced an action programme to challenge elder abuse. Part of this programme was the eLearning module 'Elderly people in safe hands' for health care professionals. The aim of this study was to investigate the results of this eLearning module and to determine the factors which make healthcare professionals motivated to participate in web-based education. Mixed methods were used to obtain insight into the effects of the module. The test results of a pre-test and a post-test were compared. Also, a Self-Efficacy Scale was used to find out whether the course members felt capable of dealing with elder abuse, to determine the effect of the module on people's self-efficacy in dealing with the abuse of elderly people. The results of this study show a positive effect of the module on the knowledge of the healthcare professionals. Furthermore, the module has a positive effect on the course members' estimation of their efficacy in dealing with the abuse of elderly people after having finished the module. These findings were confirmed in telephone interviews with course members. Telephone interviews were also held with three healthcare organizations to determine the factors which motivate healthcare professionals to participate in web-based education. A short period of time to complete the module in combination with a good guidance from the organization were considered important factors.
\end{abstract}

Key Words: eLearning, Elder abuse, Healthcare, Education, Nursing, Medicine

\section{INTRODUCTION}

There is a growing interest in elder abuse worldwide and an aspect of this is likely due to the exponential growth in the elderly population. By the year 2025, the global population of those aged 60 years and older might more than double, from 542 million in 1995 to about 1.2 billion. ${ }^{[1]}$ The prevalence of elder maltreatment in the community is high (about $3 \%$ ) and may be as high as $25 \%$ for older people with high support needs. ${ }^{[2]}$
It is important for healthcare professionals to be capable of recognizing elder abuse. The recognition of elder abuse is important to prevent abuse of elderly people and/or to put an end to the elder abuse. There are several definitions of elder abuse being used. The $\mathrm{WHO}^{[1]}$ defines elder abuse as "a single or repeated act, or lack of appropriate action, occurring within any relationship where there is an expectation of trust which causes harm or distress to an older person".

There are several forms of elder abuse: physical, psycholog-

*Correspondence: Josien A. Caris; Email: Josien.Caris@han.nl; Address: HAN University of Applied Sciences, Netherlands. 
ical, financial and sexual abuse. The current estimation of prevalence in the Netherlands, still based on early research, ${ }^{[3]}$ indicates that one out of twenty elderly people (65 years of age and older) is being abused. The actual numbers of reporting elder abuse is presumed to be much lower than its true occurrence. According to Plaizier and Klerk, ${ }^{[4]}$ the actual numbers of elder abuse are difficult to determine. No matter what method is being used, a part of the victims stays out of sight. $^{[4]}$

Much research in recent years has focused on the prevalence of elder abuse, ${ }^{[4-7]}$ attitudes and knowledge of professionals regarding elder abuse, ${ }^{[8-10]}$ assessment tools to rate elder abuse $^{[11,12]}$ and knowledge of risk factors relating to elder abuse. ${ }^{[13,14]}$ Although many researchers have addressed the need for professional education, there is little research on the development and use of educational programmes. The WHO states that "education involves not only teaching new information but also changing attitudes and behavior, and is thus a fundamental preventive strategy" ${ }^{[1]}$ It would be useful to focus future research on determining the best, most effective ways and venues for providing professional education on elder abuse and neglect. ${ }^{[12]}$ Harries and colleagues ${ }^{[15]}$ investigated the effects of an educational program to detect financial abuse of elderly people. The results showed a positive effect. According to Grol and Wensing ${ }^{[16]}$ factors which motivate healthcare professionals to participate in web-based education are a motivated team, the involvement of the people, the overall context, the use of a timetable and available resources. Dankbaar ${ }^{[17]}$ found four important factors in the process of implementing web-based intervention in medical education: direction, commitment, guidance and communication.

The Dutch Ministry of Health, Welfare and Sport introduced an action programme to combat elder abuse. ${ }^{[18]}$ Part of this programme has been the development of an eLearning module 'Elderly people in safe hands' for healthcare professionals. The purpose of this module was to increase professional awareness of the problem of elder abuse and the development of intervention skills.

\subsection{The eLearning module 'Elderly people in safe hands'}

The eLearning module formed part of a learning path. The learning path started with a knowledge test (pre-test), followed by the eLearning module and ended with a post-test. There were three modules developed for Licensed Practical Nurses (LPN), Registered Nurses (RN) and Physicians. The three modules are designed within the same format providing the healthcare professionals information about the forms of elder abuse, the risk factors relating to elder abuse and also Published by Sciedu Press their own attitude towards elderly persons and the abuse of elderly people.

Each module contains of specific questions, cases and video material for the three target groups due to the different roles and tasks these professionals have. Also, the module for the LPN was made easier to read. The learning path can be followed at any time and any place.

\subsection{Blended learning}

The healthcare professionals were able to register on an individual basis. The healthcare organization also was offered a group account for their own healthcare professionals. A group account allowed these organizations to obtain an overview of their results. These results might be useful in organizing extra training programmes i.e., blended learning (b-learning). We expect to find differences between the healthcare professionals who follow an additional training programme (b-learning) and those who don't. B-learning is a combination of eLearning and face-to-face instruction. In a study of Dankbaar ${ }^{[17]}$ the combination of eLearning and face-to-face instruction was found to be more effective than face-to-face instruction only. Blended courses have the potential to increase student learning outcomes in comparison with equivalent fully online courses. ${ }^{[19]}$

\subsection{Study aims}

The study aims were to investigate the results of the eLearning module and to determine the factors which motivated healthcare professionals to participate in web-based education.

The research questions were:

- What is the effect of the eLearning module on the knowledge of healthcare professionals?

- How capable are the healthcare professionals in recognizing elder abuse?

- How competent do the professionals feel in dealing with elderly people who had experienced abuse?

- What are possible differences between the individual members and the group members (b-learning)?

- What are the factors which motivate healthcare professionals to participate in web-based edu-cation?

\section{METHODS}

\subsection{Design}

In order to test the results of the eLearning module a quantitative approach as well as a qualitative approach with a descriptive design was used. Mixed methods were therefore used to obtain insight into the effects of the module; a greater knowledge about elder abuse on one hand and a 
greater awareness of the abuse on the other hand. A qualitative approach with a descriptive design was used to get better insight in the quantitative date and to determine the factors which stimulate the participation in web-based education. All of the data were collected in the period October 2012 to the end of November 2013.

\subsection{Quantitative}

The healthcare professionals who conducted the module (course members) completed a knowledge test (pre-test) prior to the eLearning module $(\mathrm{N}=1,825)$. After conducting the module for $70 \%$ or more it was possible to take a post-test. The tests were submitted to an expert team and checked upon variety of subjects and questions according to the aims of the eLearning module (face validity). In this study test results of the group that finished both tests $(\mathrm{N}=1,203)$ were compared in order to test for possible differences.

All course members who completed the pre-test $(\mathrm{N}=1,825)$ were asked to fill in a self-constructed Self-Efficacy Scale (SES) to find out whether the course members felt capable in dealing with elder abuse. The information collected was strictly confidential and remained anonymous. People's es- timation of their own efficacy predicted how they would actually deal with something in real time. ${ }^{[20]}$

As shown in Table 1, the SES was used at three time points: after the pretest (SES1) ( $\mathrm{N}=385)$, after conducting the module plus the post-test $(\mathrm{SES} 2)(\mathrm{N}=279)$ and after a period of six months (SES3) $(\mathrm{N}=107)$. By doing so we were able to determine the effect of the module on people's estimation of their own efficacy in dealing with the abuse of elderly people. As well, some of the course members followed an extra training regarding elder abuse, organized by their own healthcare organization. In order to find out the differences between the course members who followed an extra training and those who didn't, SES3 was scheduled after a period of 6 months.

The characteristics of the three groups of course members (SES) were comparable. The course members, predominantly women $(93.7 \%)$, most of them work as a Licensed Practical Nurse $(44.5 \%)$ (Registered Nurses: $31.5 \%$; Physicians: $3.4 \%$ ) in home care. $31 \%$ of the course members at SES3 $(\mathrm{N}=33)$ followed an additional training organized by their own healthcare organization.

Table 1. Overview course members (test and SES)

\begin{tabular}{|c|c|c|c|c|c|}
\hline $\begin{array}{l}\text { Course members } \\
\text { pre-test }\end{array}$ & $\begin{array}{l}\text { Course members } \\
\text { pre-test and post-test }\end{array}$ & & $\begin{array}{l}\text { Course members } \\
\text { who filled in SES1 }\end{array}$ & $\begin{array}{l}\text { Course members } \\
\text { who filled in SES2 }\end{array}$ & $\begin{array}{l}\text { Course members } \\
\text { who filled in SES } 3\end{array}$ \\
\hline \multirow[t]{2}{*}{1,825} & 1,203 & & 384 & 281 & 107 \\
\hline & & $\begin{array}{l}\text { Course members who followed an } \\
\text { extra training (b-learning group) }\end{array}$ & 111 (29\%) & 87 (31\%) & 33 (31\%) \\
\hline
\end{tabular}

\subsection{Data analysis}

For the data analysis the Statistical Package for Social Sciences (SPSS 20) was used.

(1) The means of the test results (pre- and post-test) of the three target groups were compared by using a pairedsamples $t$-test.

(2) The Self-Efficacy Scale contains 21 statements on elder abuse and is reliable $(\alpha=.95)$. An example of a statement is: I believe I'm capable of recognizing abuse of elderly people. The participant can choose on a six point Likert scale between: Strongly disagree (1) and Strongly agree (6).

\subsection{Qualitative}

A qualitative approach was undertaken to achieve a better understanding of the quantitative data and to find the factors which motivated healthcare professionals to participate in this web-based education programme.

All course members $(\mathrm{N}=385)$ who filled out the questionnaire the first time (SES1) were invited to participate in an individual interview by phone. A total of 96 course members indicated that they were interested. Finally 22 course members agreed to participate. All of these participants were female, most of them Registered Nurses $(\mathrm{RN})(\mathrm{N}=9)$ and Licensed Practical Nurses (LPN) $(\mathrm{N}=11)$ and two of them physicians. The interviews, which lasted 20-30 minutes, were semi-structured. The topics of the interview were: the attitude towards abuse of elderly people and towards the abuser, the way of performing in case of a possible abuse of an elderly person and the opinion about blended learning. The interviews were held after completing SES 3.

Three representatives of healthcare organizations (home care) with a lot of course members $(\mathrm{N}=500, \mathrm{~N}=170, \mathrm{~N}=100)$ who completed the module were also approached. These representatives (all three female) were approached by email. All three of them were interested and participated in an individual interview by phone. The interviews, which lasted 20 minutes, were semi-structured. The topics were: the way the module was implemented within the organization and the factors that helped the professionals to participate in web-based 
education.

All qualitative data collected was strictly confidential and remained anonymous.

\subsection{Data analysis}

The 22 interviews with the participants and the 3 interviews with the representatives were recorded and transcribed verbatim. Data were analyzed simultaneously and separately by two researchers and the two analyses were compared and contrasted.

\section{Results}

\subsection{Findings of the quantitative study}

\subsubsection{Level of knowledge}

The results of the knowledge tests show that the averages of the post-test are higher compared to the averages of the pre-test (see Table 2). The level of knowledge of the three target groups was increased. The Physicians (86.9) achieved the highest mean score, followed by the Registered Nurses (81.4). The Licensed Practical Nurses achieved the lowest mean score (79.3).

Table 2. Mean scores (Descriptives) of the pre- and post-test $(\mathrm{N}=1,203)$

\begin{tabular}{lll}
\hline & $\begin{array}{l}\text { Mean } \\
\text { pre-test }\end{array}$ & $\begin{array}{l}\text { Mean } \\
\text { post-test }\end{array}$ \\
\hline Licensed Practical Nurses & 62.8 & 79.3 \\
Registered Nurses & 66.7 & 81.4 \\
Physicians & 64.6 & 86.9 \\
\hline
\end{tabular}

A paired-samples $t$-test $(\mathrm{N}=1,203)$ was conducted to compare the averages of the pre-test and post-test. There was a significant difference in the scores at the pre-test $(M=64.6$, $\mathrm{SD}=7.6)$ and the post-test $(\mathrm{M}=80.7, \mathrm{SD}=8.6)$ conditions; $t(1,202)=-56.7, p<.001)$. The scores of the three target groups separately also showed significant differences at the pre-test and the post-test points.

\subsubsection{Self-Efficacy Scale (SES)}

The average scores at the three moments of measurement of all 21 statements of the SES are shown in Table 3. The average score was the highest at SES2 (after conducting the module). After six months (SES3) the scores decline although the scores are still higher than the scores at SES1 (after the pre-test).

An One-way ANOVA test was conducted to compare the results of the different moments of measurement (see Table $3)$. There was a significant difference in the scores at SES1 $(\mathrm{M}=99.2, \mathrm{SD}=11.9)$ and SES $2(\mathrm{M}=103.1, \mathrm{SD}=13)(p$ $<.001)$. There was no significant difference in the scores at Published by Sciedu Press
SES1 and SES3 and at SES 2 and SES3 $(p>$.05) (see Table 4).

Table 3. Mean scores (Descriptives) of SES1, SES2, SES3

\begin{tabular}{lll}
\hline & $\mathbf{N}$ & Mean \\
\hline SES1 & 384 & 99.2 \\
SES2 & 281 & 103.1 \\
SES3 & 107 & 101.5 \\
\hline
\end{tabular}

Table 4. Multiple comparisons (Bonferroni) of SES1, SES2, SES3

\begin{tabular}{llll}
\hline & & Mean differences & Sig. \\
\hline SES1 & SES2 & -3.93 & .000 \\
& SES3 & -2.23 & .245 \\
SES2 & SES1 & 3.93 & .000 \\
& SES3 & 1.64 & .686 \\
SES3 & SES1 & 2.29 & .245 \\
& SES2 & -1.64 & .686 \\
\hline
\end{tabular}

The items of the SES with the highest mean score of the total group at all three moments of measurement are (range 1-6):

- I believe I'm capable of making the abuse of elderly people open to discussion in my team (SES1: 5.15SES2: 5.20-SES3: 5.22).

- I believe I'm capable of talking with other healthcare professionals about the abuse of elderly people (SES1: 5.07-SES2: 5.13-SES3: 5.10).

The items of the SES with the lowest mean score of the total group at all three moments of measurement are:

- I believe I'm capable of having a conversation with the abuser when I suspect the abuser of abusing an elderly person (in the domestic circle) (SES1: 4.45-SES2: 4.60-SES3: 4.50).

- I believe I'm capable of evaluating the risk of actual abuse of an elderly person (SES1: 4.46-SES2: 4.80SES3: 4.68).

\subsection{3 eLearning versus b-learning}

The total average scores of the course members who followed an extra training regarding elder abuse organized by their own healthcare organization (the b-learning group) and those who didn't were compared. A similar outcome was found. The average score was the highest at SES2 (after conducting the module). After six months (SES3) the scores declined although the scores were still higher than the scores at SES1.

\subsection{Findings of the qualitative study}

\subsubsection{Recognition of elder abuse}

Almost all participants reported that the eLearning module made them more aware of the possible abuse of elderly peo- 
ple. They reported that they now know the actual extent of the problem and how elder abuse can be recognized.

"I didn't know it was such a big problem."

"I only knew of the physical aspects of the abuse of elderly people. I didn't expect that there could be also psychological effects."

Many participants are more aware of the fact that the abuse of elderly people can take place within their own healthcare organization.

"Actually I'm aware now of the possibility that the abuse of elderly people can happen at my own workplace".

Most of the participants feel that they are more capable of identifying possible abuse of elderly people. After conducting the eLearning module they are more alert to any signals.

"I'm more capable of recognizing maltreatment, I notice more than before..."

"The module emphases the importance of mentioning what is happening".

"I'm ashamed it's possible that I've missed signals in the past".

Almost all participants felt they are capable of making the abuse of elderly people open to discussion in their team prior to the module. After conducting the module they still feel the same about this.

Most of the participants mention that they are more capable of organizing help when there is a serious suspicion of elder abuse. Some participants feel that this is the most difficult part.

"What seems to me as really complicated is making a good estimation of the maltreatment. Matters are unpredictable and so are people".

\subsection{2 eLearning versus b-learning}

Only three of the 22 interviewees participated actually in a blended learning group. The majority of the 19 participants who didn't follow a blended learning group found that the module offered enough information. A few considered that extra training could be useful; primarily to share experiences with each other.

"While I was conducting the eLearning module, I missed contact with colleagues."

\subsubsection{The factors which motivate healthcare professionals to participate in web-based education}

The three healthcare organizations implemented the eLearning module in different ways. One organization spent a lot of time communicating about the abuse of elderly people in addition to the module. Another organization used only the module as a tool to inform the healthcare professionals about the abuse of elderly people. Only one organization verified who had started and finished the module. By doing so they could detect possible problems. The professionals who had not started the module yet were motivated to do so.

Also, the time in which the module had to be completed differed amongst the organizations from one month to 1 year. The organization that originally allowed the professionals to conduct the module within two months extended this period several times. All three organizations considered adequate resources/facilities (at home and at the workplace) as very important. Within one organization the sound of the computer did not work. For this reason, the professionals had to conduct the module at home outside working hours.

In one organization the staff members were very enthusiastic and this attitude motivated the healthcare professionals within the organization. In another organization the staff was less enthusiastic (they found the module too long and repetitive) and this discouraged the other professionals.

\section{Discussion}

The effects of Internet-based instruction have been extensively researched, but not in combination with the theme of elder abuse. Cook and colleagues ${ }^{[21]}$ conducted a systematic review of all studies of Internet-based instruction involving health professional learners. The results showed that Internet-based instruction has a positive effect on knowledge, skills and behaviour and had positive effects on patient care. ${ }^{[21]}$ None of these studies focused on the abuse of elderly people. Alt and colleagues ${ }^{[22]}$ conducted a systematic review regarding the effectiveness of an educational program to improve recognition and reporting of elder abuse. Unfortunately many of the studies do not give enough process details of the programs to be replicable. In addition, the articles do not describe the effects of a web-based intervention.

\subsection{The results of the eLearning module}

The goal was to find possible effects of the eLearning module. It can be noticed that the averages of the post-test are significant higher than the averages of the pre-test and that the Physicians have got the highest mean score at the post-test followed by the RN and the LPN. This ranking is in line with their level of education. The course members who completed the SES were a small selection of the total group of course members who conducted the module. These course members might not have been comparable to the other course members. Unfortunately there was no opportunity to compare the selected group with the course members who didn't fill in the Self-Efficacy Scale. It is possible that these course members have got a higher score at the pre-test and post-test than the 
course members who did not participate.

\subsection{Self-Efficacy Scale (SES)}

The eLearning module had a positive effect on the course members' estimation of their efficacy in dealing with the abuse of elderly people. The first SES measurement took place immediately after the pre-test. It would have been better to organize this moment before the pre-test. Unfortunately course members could only be included after having finished the pre-test. However, a comparison of the three moments of measurement could be made. Furthermore, the last SES measurement took place after six months. It is possible that other factors may have influenced individuals awareness regarding elder abuse. In this period there was attention for this subject on the television.

The average score is the highest at SES2 (after conducting the eLearning module). The results show that there is a significant difference between SES1 and SES2. Unfortunately, the positive effect on self-efficacy does not remain at the same level after a period of six months.

There are no results known about the different SES scores of the Physicians, Registered Nurses and Licensed Practical Nurses. Further research is needed to find out possible differences between the disciplines.

The course members feel most competent about making the abuse of elderly people open to discussion in their team. Furthermore, they feel that they are capable of talking with other health professionals, for example doctors, who are involved with the elderly person. Professionals felt least capable of recognizing the risk factors of the abuser, having a conversation with the abuser and evaluating the risk of actual abuse of an elderly person. Healthcare organizations should pay more atten-tion to these items. This was also confirmed in the individual interviews.

\subsection{Recognition of elder abuse}

Twenty-two individual course members participated in the qualitative study. It is possible that they were a more motivated part of the total group. However, the proportions of this target group are comparable with the total group: most of them are LPN's and RN's and only a minority were Physicians. After conducting the eLearning module they became more aware of the problem of elder abuse and of possible signals of elder abuse. As a result, they felt more capable of recognizing the abuse of an elderly person. These results are in line with the findings of the SES measurement.

\section{4 eLearning versus b-learning}

The mean score of the b-learning group was at SES3 almost the same compared to the total group of course members.
Unfortunately it is unclear which persons of the b-Learning group already completed an extra training prior to SES3. If they did not, this might explain the same mean score at SES3. If they did, the professionals who followed an extra training (b-learning group) might have become more aware of their capabilities regarding to the abuse of elderly people due to the eLearning module.

\subsection{Motivating factors}

Chiu and colleagues ${ }^{[23]}$ concluded that the social factor is essential in supporting each other to use web-based continuing learning. Two important motivating factors have been found in the interviews with the healthcare organisations in accordance with Grol and Wensing: ${ }^{[16]}$ the period of time in which the eLearning module has to be completed and an adequate supervision of the staff. A period of a month to complete the module seems to be enough; the majority of the course members was able to finish the module within this period. Furthermore, it is important to supervise and to motivate the professionals and to detect problems when they occur. A good guidance within the organization has also been found by Dankbaar. ${ }^{[17]}$

\subsection{Limitations of the study}

Although the study did not include observation of actual behaviour of the course members, the expectation is that increased knowledge and self-efficacy and open-mindedness to signals of abuse will lead to more adequate behaviour of the healthcare professionals.

\section{Conclusion}

This study provides insight into the effects of an eLearning module regarding the abuse of elderly people. The module had a positive effect on the knowledge of the different healthcare professionals. Secondly, the module had a direct positive significant effect on the self-efficacy of these professionals in dealing with the abuse of elderly people. These results were confirmed in the interviews. This positive significant effect did not maintain after a period of time although the scores at SES3 are still higher than the scores at SES1 (after the pre-test).

The professionals felt most competent about making the abuse of elderly people open to discussion in their team and with other healthcare professionals who are involved in the care of elderly.

The results of the pre-test and the post-test of the eLearning group and the b-learning group were comparable. B-learning did not lead to additional competence. Further research is necessary to obtain more relevant information about the blended learning group. 
The study also shows the importance of a short period of time to complete the module in combination with a good guidance from the organization.

\section{CONFLiCTS OF INTEREST Disclosure}

The authors declare that there is no conflict of interest.

\section{REFERENCES}

[1] WHO. World report on violence and health. WHO, Geneva. 2002.

[2] WHO. European report on preventing elder maltreatment. WHO Regional Office for Europe. 2011.

[3] Comijs HC, Post AM, Smit JH, et al. Elder abuse in the community: Prevalence and consequences. Journal of the American Geriatrics Society. 1998; 46(7): 885-888. PMid:9670877 http: //dx.doi.org/10.1111/j.1532-5415.1998.tb02724

[4] Plasier I, Klerk M. Ouderenmishandeling in Nederland. Inzicht in kennis over omvang en achtergrond van ouderen die slachtoffer zijn van ouderenmishandeling. SCP. Den Haag. 2015.

[5] Daly JM, Merchant ML, Jogerst GJ. Elder Abuse Research: A Systematic Review. Journal of Elder Abuse \& Neglect. 2011; 23: 348 365. PMid:21978292 http://dx.doi.org/10.1080/08946566. 2011.608048

[6] De Donder L, Luoma M, Penhale B, et al. European map of prevalence rates of elder abuse and its impact for future research. Eur J Ageing. 2011; 8: 129-143. http://dx.doi.org/10.1007/s1043 3-011-0187-3

[7] Fulmer T, Strauss S, Rusell SL, et al. Screening for elder mistreatment in dental and medical clinics. Gerondontology. 2012; 29(2): 96105. PMid:22225431 http://dx.doi.org/10.1111/j.1741-2 358.2010.00405.x

[8] Almogue A, Weiss A, Marcus EL, et al. Attitudes and knowledge of medical and nursing staff toward elder abuse. Archives of Gerontology and Geriatrics. 2010; 51(1): 86-91. PMid:19775762 http://dx.doi.org/10.1016/j.archger.2009.08.005

[9] Häggström E, Bruhn A. Caregivers' attitudes to education and supervision in work with the older people in a nursing home. Nurse Education Today. 2009; 29: 850-854. PMid:19500887 http://dx .doi.org/10.1016/j.nedt.2009.05.002

[10] McCreadle C, Bennett G, Gilthorpe MS, et al. Elder abuse: do general practitioners know or care? Journal of the Royal Society of Medicine. 2000; 93: 67-71.

[11] Conrad KJ, Iris M, Ridings JW, et al. Self-report Measure of Psychological Abuse of Older Adults. The Gerontologist. 2010; 51(3): 354-366. PMid:21173437 http://dx.doi.org/10.1093/geron t/gnq103
[12] Imbody B, Vandsburger E. Elder Abuse and Neglect: assessment tools, interventions, and recommendations for effective service provision. Educational Gerontology. 2011; 37: 634-650. http: //dx.doi.org/10.1080/15363759.2011.577721

[13] Chau-Wai Yan E, So-Kum Tang C. Elder Abuse by Caregivers: A Study of PrevaLence and Risk Factors in Hong Kong Chinese Families. Journal of Family Violence. 2004; 19(5): 269-277. http: //dx.doi.org/10.1023/B: JOFV.0000042077.95692.71

[14] Penhale B. Responding and Intervening in Elder Abuse and Neglect. Ageing Int. 2010; 35: 235-252. http://dx.doi.org/10.1007/s 12126-010-9065-0

[15] Harries P, Davies M, Gilhooly K, et al. Educating novice practitioners to detect elder financial abuse: a randomized controlled trial. BMC Medical Education. 2014. http://dx . doi .org/10.1186/1 472-6920-14-21

[16] Grol R, Wensing M. Implementatie. Maarssen, Elsevier Gezondheidszorg. 2006

[17] Dankbaar MEW. De effectiviteit van e-learning en de implementatie in het medisch onderwijs. Tijdschrift voor Medisch Onderwijs. 2009; 28(5): 212-222. http://dx.doi.org/10.1007/BF03081798

[18] VWS, 2012. 'Ouderen in veilige handen': het Actieplan. Ministerie van Volksgezondheid, Welzijn en Sport, Den Haag.

[19] Dziuban C, Hartman J, Moskal P. "Blended learning". 2004.

[20] Bandura A. Self-Efficacy: The Exercise of Control. Freeman. 1997.

[21] Cook DA, Levinson AJ, Garside S, et al. Internet-Based Learning in the Health Professions: A Meta-analysis. American Medical Association. 2008; 300(10): 1181-1196. PMid:18780847 http: //dx.doi.org/10.1001/jama.300.10.1181

[22] Alt KL, Nguyen AL, Meurer LN. The Effectiveness of Educational Programs to improve Recognition and Reporting of Elder Abuse and Neglect: A Systematic Review of the Literature. Journal of Elder Abuse \& Neglect. 2011; 23: 213-233. PMid:27119527 http://dx.doi.org/10.1080/08946566.2011.584046

[23] Chiu Y, Tsai C. The roles of social factor and internet self-efficacy in nurses' web-based continuing learning. Nurse Education Today. 2014; 34: 446-450. PMid:23669599 http://dx.doi .org/10.10 $16 / j$. nedt. 2013.04 .013 